\title{
Disparity between Ideals and Reality in Curriculum Construction: The Case of the Lebanese English Language Curriculum
}

\author{
Kassim Ali Shaaban \\ English Department, American University of Beirut, Beirut, Lebanon \\ Email: shaaban@aub.edu.lb \\ Received November 6 ${ }^{\text {th }}, 2013$; revised December $6^{\text {th }}, 2013$; accepted December $15^{\text {th }}, 2013$
}

\begin{abstract}
Copyright (c) 2013 Kassim Ali Shaaban. This is an open access article distributed under the Creative Commons Attribution License, which permits unrestricted use, distribution, and reproduction in any medium, provided the original work is properly cited. In accordance of the Creative Commons Attribution License all Copyrights (C) 2013 are reserved for SCIRP and the owner of the intellectual property Kassim Ali Shaaban. All Copyright @ 2013 are guarded by law and by SCIRP as a guardian.
\end{abstract}

This paper describes the disparity between the principles, guidelines, suggested themes, organization, methodology, classroom activities, and assessment outlined in the thematic, content-based English language curriculum adopted by the Lebanese government in 1997 and the classroom realities and other contextual factors that have hampered its proper implementation. The paper shows that the curriculum is designed in line with international ESL/EFL standards as it has clear goals, objectives, and performance indicators as well as sound perspectives on instruction, material selection and adaptation, and evaluation guidelines. These perspectives are based on widely accepted theoretical views in language acquisition and best practices in English language education. However, the content-based curriculum normally demands a high level of language proficiency and content and pedagogical knowledge from teachers, and it is highly dependent on the availability of adequate resources and ongoing professional development programs. The educational context in Lebanon still suffers the effects of the 1975-1990 civil war in these areas, which has made the implementation fraught with all sorts of problems.

Keywords: Content-Based Curriculum; Lebanese Educational Context; Implementation Issues

\section{Introduction}

When committees consisting of academic experts, researchers, and practitioners are entrusted by their country's educational authorities with the vital task of developing a curriculum for a certain school subject, they normally start by identifying the country's general educational philosophy, its overall developmental priorities, goals of teaching that subject, and the available human and physical resources. Their next move would be to consider international trends and research findings in their field, model their work after well-known successful experiences in other contexts, and create a unique product that is compatible with global educational trends and, at the same time, addresses the needs and special characteristics of the local context. No matter how hard committees try to produce an ideal product, only the process of translating the curriculum into classroom teaching and learning will reveal if there are glitches in the system in the form of inherent shortcomings or contextualized implementation problems that need to be addressed. In most instances, both inherent and contextualized issues emerge. It is for this reason that educational experts consider curriculum evaluation as a regular, natural procedure in any educational context (Bradley, 1985; Brandt, 1981; Eisner, 1979).

Periodic curriculum evaluation is usually carried out in order to ensure that the educational process of teaching and learning is proceeding in a smooth manner, that the set educational goals and instructional objectives are achieved, and that timely remedial measures are introduced to deal with unforeseen problems and to keep the learning process on track. The process of evaluation involves collecting in a systematic manner, all pertinent information for the purpose of assessing and evaluating the effectiveness of the curriculum in contributing to successful learning experiences (Marsh, 2004; Nichols, Shidakar, \& Singer, 2006; A-Jardani, 2012). The task of evaluation could be entrusted to specialists in the Ministry of Education, external examiners, or the primary stakeholders (schools, teachers, and students) among other possible entities. Researchers in the area of language learning could also be involved in the process on their own initiative.

Curriculum evaluation includes all aspects of the curriculum and its implementation: instructional objectives and learning outcomes; classroom interaction and teaching methodology; resources and facilities; textbooks and other instructional materials; teachers; and assessment.

In this paper, we will offer an evaluation of the current Lebanese English language curriculum, which has been in place since 1998, and the issues and problems that have arisen during the process of implementation. The study will apply content analysis to the curriculum document and, at the same time, synthesize and analyze the evaluations of the curriculum by interested researchers and concerned practitioners (Bell, 1999; 
Kripendorff, 1980; Marsh, 2004). The curriculum evaluations were taken from special reports, journal articles, and theses on the subject.

\section{Background of Curriculum Development}

A new English language curriculum was an urgent need after the civil war came to an end in 1990. During the civil war, the whole educational system was in shambles, and every educational institution was doing things the way it desired without any supervision or guidance from educational authorities. The public education system was the main victim of the war as it reached a state of near collapse (Bashshur, 2004). Private educational institutions, on the other hand, went through all kinds of tribulations, but they managed to survive, sustaining minor damages. The Lebanese government that came to power after the 1990 Taif Agreement set as its agenda the total development and reconstruction of the country; it looked at education as the means for reconstructing the Lebanese identity and rebuilding the Lebanese citizen. The development of new curricula in all subject matter areas, entrusted to the Center for Educational Research and Development (NCERD) was seen as the most efficient way of bringing the country up-to-date educationally and having it rejoin the civilized world (NCERD, 1994). The new curricula were intended to bring about a new educational order where people come together under one unified national and educational agenda without restricting the diversity, openness to other cultures, and creativity that allowed the country's institutions to survive, though not unscathed, all the tough times (NCERD, 1995). In language education, diversity and openness meant moving in the direction of trilingualism through: strengthening the mother tongue, Arabic, as the symbol of identity; teaching one foreign language as of Grade 1; and introducing a second foreign language as of Grade 7 (Shaaban \& Ghaith, 1999; Diab, 2006; Zakharia, 2010).

The end of the civil war and the introduction of a new reconciliation accord that stressed unity, development and reconstruction brought to the forefront the importance of the English language locally, regionally, and internationally (Shaaban, 1997). The traditionally French-educated sectors of society were demanding English, without giving up French that was cherished for its historical and cultural value. The curriculum had to be different from what was before due to the rising needs for higher levels of proficiency in a globalized world and the use of the language as a medium of instruction in subject matter areas. As such, the new English curriculum had to address all these needs and cater to people's demands and expectations regarding the best possible outcomes for English language teaching and learning. Internationally, the standards and learning outcomes movement had started to take hold at the time the development of a new curriculum was being considered, and espousing its principles and systematic approach would have been a step in the right direction.

\section{Curriculum Construction}

A committee of 35 Lebanese English language and literature experts and practitioners participated in the project of curriculum development; they consisted of university professors, Ministry of Education English language experts, and classroom teachers. The author served as the General Coordinator of the project, chairing a Coordinating Committee of 8 members and a
General Committee that added another 26 classroom practitioners.

The first task of the General Committee (henceforth the Committee) was to critically review and evaluate the old curriculum that had been in place since the year 1968; it followed the audio-lingual approach, which was rooted in behaviorist psychology. Language learning was thought of as a form of habit formation achieved through pattern practice and drilling activities. The approach ignored the development of thinking and study skills and authentic communication; the absence of these elements contributed to the development of a language education system based on memorization (Shaaban, 2005). The 1968 curriculum has not managed to prepare students adequately for the use of English as a medium of instruction in mathematics and sciences in schools and as the language of university education in general. It has helped students develop their basic interpersonal communication skills (BICS) but was not as successful in developing their cognitive academic language proficiency (CALP) (see Cummins (1979) for an explanation of the differences between BICS and CALP).

The Coordinating Committee then looked at publications reflecting international trends in teaching English as a second/ foreign language. More specifically, the Committee considered the English National Curriculum in England and Wales (Carter, 1991); the Threshold Level for Modern Language Learning in Schools (Van Ek, 1991); and the American Council of Teachers of Foreign Languages (ACTFL) proficiency guidelines. The Committee was also fortunate to get access to and consult the draft of the pre-K-12 TESOL standards that was being worked upon at the time. The Committee's ultimate purpose was to create a curriculum that would incorporate international trends in ESL/EFL curricula and apply some of its principles and practices in the Lebanese context in a way that does not negate the independent character of the curriculum as determined by the Lebanese context and the immediate needs of the learners.

\section{The Curriculum}

The Committee aimed to produce "a working curriculum that espouses modern theories of foreign language acquisition and recent trends in curriculum design and teaching methodologies” (Shaaban \& Ghaith, 1997: p. 200). The final product was The English Language Curriculum which introduced "a thematic, content-based curriculum that stresses skill integration, cooperative learning, autonomy in learning, cultural awareness, and study habits" (Shaaban, 2005: p. 118). The following pedagogical principles provided the guidelines for the curriculum: Learning language is learning to communicate; language use varies according to context, academic and other purposes, and medium; learning language gives exposure to a new culture allowing for understanding, appreciation, and respect for cultural diversity; effective language learning occurs when students engage in meaningful, purposeful, and relevant tasks; and integrated language skills make for better learning (NCERD, 1998: p. 5).

\section{Structure of Curriculum}

\section{Goals and Objectives}

Three goals were set for the curriculum: social interpersonal communication: academic achievement, and social-cultural 
interaction. These goals were translated into seven objectives: interpersonal communication; academic communication; preparation for college; critical thinking; intercultural understanding and appreciation; positive attitudes towards target language and culture; and working with others. These objectives were then turned into measurable learning outcomes and labeled as performance tasks.

\section{Content}

The basic idea behind having a thematic, content-based curriculum was that "integrating and organizing instruction around meaningful themes would be effective in achieving the communicative, social, and academic goals set for teaching English in the country" (Shaaban \& Ghaith, 1997: pp. 200-201). In choosing themes for the curriculum, there was a deliberate decision to choose socially and developmentally appropriate themes taken from the learners' immediate learning context, such as the self and the other, family and friends, and the neighborhood in the lower classes, and gradually moving into more encompassing themes that constitute part of the learners' expanding awareness of the world they live in and the issues of close relevance to their lives, such as knowledge society, mass communication, new discoveries, the environment, human rights and so forth at the higher levels. Some of the themes, such as the environment and discoveries, would be readdressed in higher classes to be dealt with in more depth.

\section{Methodology}

"The curriculum aimed at involving learners in their own learning by engaging them in meaningful and interactive performance tasks as they acquire a wide range of language forms, structures, and functions needed for immediate success in an all-English curriculum at all levels of instruction” (Shaaban \& Ghaith, 1997: p. 201).

Integration of language and content was to be achieved through using "the two approaches of parallel scheduling and thematic units proposed by Block (1993)” (Shaaban \& Ghaith, 1997: p. 202). Parallel scheduling and thematic units do not require much coordination on the part of the ESL and subject matter teachers; teachers may teach the same or similar topics of study but assess each subject separately. Integration serves the purpose of helping students build strong background knowledge about a certain topic, see it from different perspectives and in different genres, and develop significant linguistic and academic knowledge and skills.

In order to encourage classroom interaction and communication, the curriculum suggested the use of cooperative learning (CL) teams of mixed abilities in carrying out learning activities in the classroom. "Essentially, cooperative learning constitutes a series of pro-social learning structures, which involve learners' working together in order to achieve some common goals according to the principles of simultaneous interaction, positive interdependence, individual accountability, and team reward" (Shaaban \& Ghaith, 1997: p. 202).These pro-social structures have been reported by CL scholars and researchers to promote social interaction, self-confidence, active student engagement, and academic achievement (Johnson \& Johnson, 1989; Slavin, 1990; Kagan, 1992). The CL “Learning Together" model of the Johnsons and the Structural model of Kagan were adopted because of their being easy to grasp and apply by the faculty and students. Emphasis was on the use of context-free student in- teractive structures such as find someone who, talking tokens, mixer review, numbered heads, inside-outside circle, round robin, think-pair-share, three-way interview, student teams achievement divisions (STAD), jigsaw I and II, and Co-Op $\mathrm{Co}-\mathrm{Op}$ (for more details on these and other CL structures, see Kagan (1992); Shaaban \& Ghaith (2005)).

In terms of language teaching methodology, the curriculum committee recommended that the communicative goals of the curriculum could be best realized through the adoption of comprehension-based approaches to foreign language teaching such as the Total Physical Response (TPR) (Asher, 2009), the Natural Approach (Krashen \& Terrell, 1983), and the Language Experience Approach (Dixon \& Nessel, 1983) due to the important role of input in the acquisition and mastery of all skill modalities, especially at the lower levels of proficiency.

\section{Instructional Materials}

The curriculum recommended that material writers and teachers receive training in how to select and adapt instructional materials that could be extracted from a variety of sources. The ultimate purpose is to have instructional materials that are appropriate to learners' age, interest, and culture; taken from authentic sources, representing different genres and modes of spoken and written language; exploitable by teachers and students, and, above all, relevant to the theme under study (Brinton, Snow, \&Wesche, 1989). The Committee provided samples for material developers to follow, emphasizing the need to select texts from different genres (newspaper and television reports, essays, debates, movies, art work, documentaries, etc...) and from various sources (encyclopedias, textbooks, magazines, videos, live debates, etc...).

\section{Assessment}

The main principle followed in assessment in the new curriculum is that tests should "include texts and activities which mirror as closely as possible those which students have been exposed to and/or are likely to meet in their future target situations" (Weir, 1993: p. 65). Another principle was that traditional tests that engender anxiety in students should be avoided and replaced by alternative assessment techniques that are part and parcel of the teaching process. This principle is easy to follow as the Lebanese curriculum has adopted the principle of automatic promotion in grades $1-3$ and facilitated promotion in grades 4 - 6; this would allow classroom teachers a great degree of freedom in evaluating their students as long as they help them attain the objectives set in the curriculum. The teacher can thus use a variety of methods of assessment, especially those that fall under the heading of "alternative assessment" in addition to traditional assessment techniques (for more on assessment in elementary school in Lebanon, see Shaaban (2000)). In higher classes, teachers were called upon to ask questions that require students to provide descriptions, personal interpretations, analysis, and critical and creative judgments. Teachers were also encouraged to use performance testing whenever possible. Finally, tests need to be based on the instructional objectives and performance tasks identified in the curriculum for each grade.

\section{Curriculum Reality as Seen by Practitioners}

If we go by official documents and reports, we can safely 
assume that neither the Ministry of Education nor NCERD has carried any evaluation or revision of the curriculum since its introduction in 1998. The analysis presented below is partly based on my own observations as an English Language specialist who had been heavily involved in the process of curriculum development and in many conversations with practitioners who had attended teacher-training workshops conducted by the American University of Beirut. I have also consulted published reports, research articles, and theses.

The review of available materials and conversations with stakeholders revealed that there are controversies, if not outright problems, in the following areas: Structure of the curriculum; goals and objectives; use of cooperative learning as a framework for classroom interaction; themes around which lessons are built; methods of teaching; teacher training opportunities and practices; the quality of the textbooks produced by NCERD; and the availability of needed resources and facilities.

\section{Structure of the Curriculum}

There was near unanimity among scholars and researchers that the new curriculum is a step in the right direction as it is has taken into account local needs, international trends, and second language acquisition research (Bacha \& Bahous, 2010; Esseili, 2011; Ghaith \& Shaaban, 1999). An evaluative report of the English as a first foreign language curriculum prepared by the Lebanese Association for Educational Studies (LAES) praised the curriculum's underlying principles and methodology (LAES, 2002). Ghaith \& Shaaban (1999) described the curriculum as "the first serious, systematic effort that has presented a detailed plan for English language teaching in Lebanon” (p. 360). However, they warned that "after years of dissociation from advances and new theories in English language teaching and learning, the English language teachers might find the curriculum overwhelming, ambitious, and even discouraging as it comprises principles, con- cepts, expressions, and practices that are totally unfamiliar to them” (p. 361).

\section{Goals and Objectives}

Most researchers and scholars considered that the organization of the curriculum into goals, instructional objectives, and performance tasks at the cycle level as well as at the grade level is in line with the communicative approach to language teaching and learning (Esseili, 2011; Ghaith \& Shaaban, 1999; Shaaban; 2005). The introduction of thinking skills, study skills, and cultural awareness were also considered positive developments. However, the goals and objectives were criticized by LAES (2002) on the grounds that "the extensive emphasis on academic language learning for the purposes of higher education reflects an underlying philosophy that places higher value on tertiary education than vocational and technical education” (p. 273). The report adds that "The Curriculum objectives do not sufficiently reflect the language learning needs of the noncollege bound students heading for the workplace, where English language skills are becoming increasingly important (p. 273). Another criticism leveled at the curriculum was that "some objectives hierarchically at a higher level are, in fact, either the same as lower level objectives or subordinate to them" (LAES, 2002: p. 274).

There is a great deal of truth in the first two remarks, and any future curriculum revisions should make sure to address them.
As for the third point regarding repeated objectives, it is obvious that the researcher has overlooked the curriculum's clear statement that "the curriculum ... is going to be spiral in nature. The same concepts and skills will be taught at various times across the grades, but with increasing levels of complexity and sophistication as we move up” (NCERD, 1998: p. 6).

\section{Cooperative Learning}

CL as a systematic approach to managing student group work was found to be difficult to apply after only a short program of training. According to the participants in a study by Sab 'ayon (2012), most teachers in public schools were asked to apply CL without understanding its principles or receiving proper training in its classroom applications leaving them one option which is "to rely on ... the images of their previous language teachers and the teaching trend followed in the school" (p. 116).

The report by LAES, (2002) states that CL is useful for groups of mixed ethnicity and linguistic background, but it poses problems in classes of students who share the same language background because in this case "any potential communication problems can be resolved using the mother tongue, making negotiation of meaning, a key aspect of second language learning, in English unnecessary” (LAES, 2002: p. 272). The report also points out that since the curriculum calls for learner-centered classes, students replace the teacher as models for English pronunciation, grammar, and expression for their peers.

In fact, these two issues raised would not be problematic if the dynamics of CL are applied properly. In the first case, the teacher, who is viewed in CL as a facilitator, should ensure that English is used to carry out classroom activities. The concern in the second case is unfounded since the teacher is always there as a resource person and a facilitator. Furthermore, since the groups are heterogeneous in terms of language proficiency, students in the team who have a relatively high proficiency could serve as good models for their peers.

\section{Themes}

One of the criticisms of the curriculum in the 2002 LAES report is that there are too many themes in some grades and not enough themes in others: 2 - 6 themes in primary grades, 13 themes in some intermediate grades, and 19 themes in grade 10 . It was argued that the fewer the themes, the easier it is to develop thematic units that form a coherent whole and to provide for both horizontal (across themes) and vertical (across grade levels) linkages that will make learning more meaningful.

One of the issues the author raised in his report to the NCERD Director was that the writing teams totally misunderstood the stand of the curriculum regarding the themes. It was envisioned in the curriculum that students in primary grades needed to develop concepts, attitudes, and values in addition to learning content. As these concepts, skills and values are essential, sticking to few particular themes and dealing with them in depth was recommended. Furthermore, at all levels, material writers and teachers could concentrate on some themes rather than others after engaging the students themselves in the choice. The high number of themes was meant to allow teachers, material writers and students to make choices. Unfortunately, many teachers and coordinators looked at these themes as the only 
possible ones and tried to work with all of them; such a practice defeats the purpose of using themes. Again, this is an area that calls for revision in the curriculum to clarify things and maybe avoid confusing practitioners by allowing too many choices.

Another issue raised in the literature was that of coordination between English and subject matter teachers. Teachers have reported that there is no coordination with subject matter teachers regarding which themes to exploit or how each teacher would present instructional materials. Again, this is another weakness that needs to be redressed.

\section{Textbooks}

Shaaban \& Ghaith (1999) remarked that the disparity between the curriculum and the NCERD textbooks was a very serious problem the teachers had to face on a daily basis. They added that "overreliance on texts from encyclopedias in some grades, absence of scope and sequence and gradation, scarcity of cooperative learning activities, and no clear evidence of exercises promoting critical thinking and study skills are all examples of serious deviations in textbooks from the curriculum plan” (p. 361). In fact, there is lack of scope and sequence among textbooks and within the same textbook as a result of the lack of coordination among textbook writing committees in different cycles and among those working on the same cycle.

Orr (2011) observed that "state schools use national textbooks [developed by NCERD]. In contrast ... private schools usually prefer imported texts ... which they claim are more appropriate; a belief not always substantiated" (p. 3). Both imported and local books do not seem to be compatible with the Lebanese context. Esseili (2011) remarked that for the private and public school teachers she had interviewed for her Ph.D. study, the main challenge was the textbook. As the curriculum allowed for the use of any instructional materials as long as they serve the curricular objectives, some schools used books prepared by foreign publishers, others used textbooks produced by publishing houses and the majority used the books produced by NCERD. Private school teachers felt that decisions on book adoption were top-down and not based on any objective criteria. The teachers felt that "students' needs and background in addition to teacher qualifications are not taken into account" (Esseili, 2011: p. 133). Books intended for use in the USA (an ESL context) were imported lock, stock, and barrel for use in the Lebanese context (EFL). "Educational objectives in these textbooks were designed for an American, not Lebanese, audience; were created to meet US assessment tests, not Lebanese official exit tests; and included classroom assessment materials for US, not Lebanese, teachers” (Esseili, 2011: p. 133). Furthermore, teachers felt that the books were culturally inappropriate introducing themes the teachers themselves do not understand, such as "garage sale”, "western life", "US currency", and "American folk traditions." Needless to say, these textbooks do not fit a Lebanese content-based EFL program, as the topics about history, geography, and local traditions do not match with the same topics in other subject matter curricula.

Regarding textual content in textbooks, one of the major principles guiding the curriculum was that the themes and texts to be explored should relate to the students' immediate environment and be developmentally appropriate, especially in the elementary classes;" "the choice of themes for each grade took into account the topics taught in other subject areas in addition to interest level and developmental and intellectual characteris- tics of the age group” (Shaaban, 2000: p. 308).Adoption of books meant for use in the US or any other country outside Lebanon would be in violation of this essential principle and curriculum guidelines. Skipping such culture-specific topics or adapting them from a comparative cultural perspective could help decrease the negative impact of the topics.

As for public school teachers, the problem was that the textbooks called Themes, the NCERD books they were using, were put together by people who have not been involved in textbook writing before. A look at the books shows clearly that there is no clear scope and sequence and no gradual development in structure and theme complexity. In one book, for instance, all the selections were taken from Encarta. When the author wrote to the NCERD Director a report that was critical of the "flat" or "chaotic" organizational structure of the textbooks, the latter's response was that he was aware of the existence of such problems but that the imposed time constraints left no room for drastic revisions.

Esseili (2011) stated that the public school teachers viewed the NCERD textbooks as "total failure", "worthless", and "not enough to create a solid foundation in the English language" (p. 136).

\section{Teachers’ Qualifications and Professional Development}

There is much talk in the literature about Lebanese English language teachers' English language proficiency and their preservice and in-service professional preparation and development. The author himself has conducted in the 1990s inservice training workshops for EFL elementary school teachers in remote areas of Lebanon and found that the teachers were having difficulty understanding what he was saying and asking him to speak in Arabic. As a result, he recommended to NCERD that such teachers should receive language training before any attempt to teach them methodology; the result was a single brief experiment of offering 35 teachers 65 hours of English. The experiment was considered helpful despite its brevity, but it was deemed too costly to continue. The reasons for these problems is that about 40 percent of these teachers do not have a BA in English Language and/or Literature and the percentage of MA holders who could serve as coordinators and leaders is rather small (13\%) (Orr, 2011: p. 6). Orr reports also that an average of 12 percent have not received any in-service training whatsoever (p. 7).

Najwa Sab 'Ayon (2012) conducted her research on the current state of the teaching of English in Lebanon on public High School teachers whose teacher certification "Kafa'a” is usually done at the College of Education at the Lebanese University. She concluded that these teachers start their professional careers on the wrong foot as the program of study for their English language Teaching Certificate is characterized by "marginalizing the observation and practicum parts of the program as well as emphasizing the theoretical, traditional content of the course and the trainers' adoption of the same traditional teaching methods" (p. 117).

The situation of EFL Professional development in private schools is a little better as teachers normally come from elite English-medium universities where they receive training in new methods of teaching, including communicative teaching and cooperative learning with a strong practical component in the form of observation and internship. Furthermore, their schools 
provide professional development, though in a sporadic, nonsystematic way. Nabhani and Bahous (2010) studied the professional development activities private school teachers were involved in and concluded that they were not effective. Participants in the study described these workshops as "fragmented, inapplicable in the classroom in terms of time and space constraints, and inconvenient as they are almost always scheduled after a school day. Another complaint voiced by the participants was about the lack of follow-up by supervisors or experienced colleagues on applying what had been learnt (Nabhani \& Bahous, 2010: p. 207).

Orr (2011), who himself has been part of teacher training activities in Lebanon, described these activities, in both public and private schools, as too theoretical in nature. He added that "given the predisposition to focus on theory, it seems unfortunate that in-service training does not seem to take full advantage of the opportunity to make the link to practical classroom application. The same problem was noted with pre-service theory classes at university.... The problem here seems to be one of failing to situate the learning in actual classroom practice” (p. 11). Orr (2011) reported also that in his experience in Lebanon as a trainer and an observer, professional development "providers often make decisions based on guesswork and predetermined ideas and materials, rather than extensive knowledge of the people who will receive training or feedback from training" (p. 2).

Though this situation is not unique to Lebanon, it remains a major issue that needs to be addressed if the curriculum is to achieve its set goals and objectives because the teacher remains the most pivotal element in the teaching and learning process (Egbert, 2006; Reid, 1999).

\section{Teaching Methods and Techniques}

According to Sab 'Ayon (2012), the teachers whose classes she observed seemed to be operating totally outside the perimeters set by the curriculum in terms of teaching methods or classroom management. She reported that "the participants drew mostly on traditional methods with few instances of group activities, not all of which were successful or achieved the objective” (p. 117)... She also wrote about some disturbing disciplinary practices such as resorting"to their negative images of strict harsh teachers when punishing their students such as asking students to stand up in the corner of the classroom or to copy the reading text three to four times on paper" (p.117).

One criticism of the curriculum in the area of methodology is that the guidelines for how to integrate skills were not clear. Some practitioners even questioned the cultural awareness principle and suggested that in the age of globalization and the growth of English in the periphery, one should concentrate on the students' culture (Esseili, 2011). This attitude is not helpful as exposure to other cultures is a natural occurrence if teachers use authentic materials from the center and if literature is used as a source of thematic texts, which the curriculum encourages (Nasr, 2001).

\section{Resources and Facilities}

The curriculum encourages the use of audiovisual aids, a computer laboratory, an LCD projector, and the Internet and other digital devices. While the acquisition of all these aids may not be problematic for many private schools, other schools, especially public schools do not place them on their list of priorities.

The curriculum also calls for the adoption of CL as a framework of classroom interaction. But in many schools, this could be rendered impossible on account of very large classes and seating issues (Esseili, 2011). Yaghi (2012) reported that "most public schools are traditional with classes organized in rows because, in most cases, they ... do not provide enough room for group-focused classes or interactive patterns” (p. 152). Similarly, Esseili (2011) reported that teachers in her study complained about the lack of resources at their schools. Some of the teaching units require the use of multimedia, but these schools have "no LCD screens, computer labs, or sound systems" (p. 137).

\section{Assessment}

Although the curriculum calls for an assessment of all skills, teachers are interested in grammar, vocabulary, reading and writing only as these are the skills and language elements tested on official national examinations. As a result students' listening comprehension and speaking abilities, especially in public schools, are not adequately developed. Furthermore, teachers are unhappy that grammar explicit teaching is delayed till Grade 4 because they feel that they need to prepare students for the official examinations early in the process of language learning (Anonymous, n.d.).

\section{Conclusion}

On the basis of the points raised above, it can be concluded that, despite the fact that the Lebanese English language curriculum has been developed by language experts and classroom practitioners in line with international standards, many factors in the Lebanese context have hampered its effective implementation. The fact of the matter is that Lebanese high school graduates, especially from public high schools, have low proficiency levels in English. Sab 'Ayon attributes this weakness to one possible explanation: the poor implementation of the curricular reforms .... and the use of more traditional teacher-centered practices of teaching instead” (p. 120). But it is really more than that. It is the clarity and accessibility of the curriculum's principles, objectives, methods, and assessment; the quality of teachers; the instructional materials; assessment; the periodic, systematic revisions of the curriculum; and the willingness of schools and educational authorities to commit to long-term investment in human and material resources.

It is important to note that, after 15 years of implementation, no serious measures have been taken to address the issues identified and raised by practitioners. The curriculum designers stressed repeatedly the experimental nature of the curriculum and the need to introduce revisions based on feedback from practitioners, experts, and researchers. It is also equally important to stress that it is not too late for curriculum revisions on the basis of reports from the field. It is never late for putting in place a systematic, continuous, professional development program; for introducing technology into English language teaching; for revising textbooks to ensure smooth gradation within the various units in a grade and from one grade to another; and for dealing with many other issues that are bound to come up in a dynamic system.

It is commendable that the Lebanese educational authorities 
are moving in the direction of trilingualism and introducing modern curricula for that purpose. However, there is fear that the already existing gap between rich and poor, symbolized by the gap between elite private and missionary schools, on the one hand, and public and commercially-motivated and run schools, on the other, is widening. The resultant deepening socioeconomic schism could create resentment that could lead to violence that threatens the fiber and fragile unity of Lebanese society. The government needs to work hard on rehabilitating the public educational sector to allow it to attain some degree of parity with the private sector; if this is not done, foreign language education, and especially English language education could turn into a tool of discrimination rather than a vehicle for enlightenment and national development. Developing or revising curricula to provide learning goals and objectives, methodology, teaching faculty, facilities, and tools of implementation that are accessible to all is the key to societal harmony and coexistence.

\section{REFERENCES}

Al-Jardani, K. S. (2012). English language curriculum evaluation in Oman. International Journal of English Linguistics, 2, 40-44.

Asher, J. (2009). Learning another language through actions (7th ed.). Los Gatos, CA: Sky Oaks Productions.

Bacha, N. N., \& Bahous, R. (2011). Foreign language education in Lebanon: A context of cultural and curricular complexities. Journal of Language Teaching and Research, 2, 1320-1328.

http://dx.doi.org/10.4304/jltr.2.6.1320-1328

Bashshur, M. (2004). Higher education in the Arab states. Beirut: Unesco Regional Bureau for Education in the Arab States.

Bell, J. (1999). Doing your research project ( $3^{\text {rd }}$ ed.) Buckinghamshire: Open.

Block, C. (1993) Teaching the language arts: Expanding thinking through student centered instruction. Boston: Allyn and Bacon

Bradley, L. H. (1985). Curriculum leadership and development handbook. Englewood Cliffs, NJ: Prentice Hall.

Brandt, R. S. (Ed.). (1981). Applied strategies for curriculum evaluation. Alexandria, VA: ASCD.

Brinton, D. M., Snow, M. A., \& Wesche, M. B. (1989). Content-based second language instruction. Boston: Heinle \& Heinle Publishers.

Carter, R. (1991) The national curriculum for English. London: The British Council.

Cummins, J. (1979). Cognitive/academic language proficiency, linguistic interdependence, the optimum age question and some other matters. Working Papers on Bilingualism, 19, 121-129.

Diab R. (2006). University students' beliefs about learning English and French in Lebanon. System, 34, 80-96. http://dx.doi.org/10.1016/j.system.2005.06.014

Dixon, C. N., \& Nessel, D. (1983). Language experience approach to reading (and writing). Hayward, CA: Alemany Press.

Egbert J. (2006). Learning in context: Situating language teacher learning in CALL. In P. Hubbard,\& M. Levy (Eds.), Teacher education in CALL (pp. 167-181). Philadelphia: John Benjamins.

Eisner, E. W. (1979). The educational imagination: On the design and evaluation of school programs. New York: Macmillan.

Esseili, F. (2011). English in Lebanon: Implications for national identity and language policy. Ed.D. Dissertation, Purdue University.

Ghaith, G., \& Shaaban, K. (1999). The prospects and problems of the new Lebanese English language curriculum. In F. Ayoub (Ed.), The new curricula in Lebanon: Evaluative review (pp. 351-364). Beirut: Lebanese Association for Educational Studies.

Johnson D. W., \& Johnson, R. T. (1989). Cooperation and competition: Theory and research. Edina, MN: Interaction Book Company.

Kagan, S. (1992) Cooperative learning. San Juan Capistrano, CA: Resources for Teachers Inc.
Krashen, S. D., \& Terrell, T. D. (1983). The natural approach: Language acquisition in the classroom. New York: Pergamon Press.

Kripendorff, K. (1980). Content analysis: An introduction to its methodology (2nd ed.). Thousand Oaks, CA: Sage.

Lebanese Association for Educational Studies (LAES) (2002). The English as a first foreign language curriculum. In Evaluation of the new educational curricula in Lebanon: Assessing objectives, structure, and lesson distribution (pp. 272-307). Beirut: Author. http://www.opentech.me/ laes/upload/editor

Marsh, C. (2004). Key concepts in understanding curriculum (3rd ed.). London: Routledge Falmer.

Nabhani, M., \& Bahous, R. (2010), Lebanese teachers' views on continuing professional development. Teacher Development, 14, 207224. http://dx.doi.org/10.1080/13664530.2010.494502

Nasr, N. (2001). The use of poetry in TEFL: Literature in the new Lebanese curriculum. CAUCE, Revista de Filologia y su Didactica, 24, 345-363.

NCERD (1995). New framework for education in Lebanon. Beirut: Author.

NCERD (1994) Plan for educational reform. Beirut: Author.

NCERD (1998). The English language curriculum. Beirut: Author.

Nichols, B., Shidakar, G., \& Singer, K. (2006). Managing curriculum and assessment: A practical guide. Ohio: Linworth Books.

Orr, M. (2011). Learning to teach English as a foreign language in Lebanon. Near and Middle Eastern Journal of Education, 2, 1-14.

Reid, D. (1999). Investigating teachers' perceptions of the role of theory in initial teacher training through Q methodology. Mentoring and Tutoring, 7, 241-255. http://dx.doi.org/10.1080/1361126990070305

Saba 'Ayon, N. (2012). Lebanese English as a foreign language teachers' conceptions of teaching and their practice in Lebanese public high schools. DPhil Thesis, University of Sussex.

Shaaban, K. (1997). Bilingual education in Lebanon. In J. Cummins, \& D. Carson (Eds.), Encyclopedia of education. Vol. V: Bilingual education (pp. 251-259). The Netherlands: Kluwer Publications.

Shaaban, K. (2000). Assessment of young learners' achievement in ESL classes in the Lebanon. Language, Culture and Curriculum, 13, 306317. http://dx.doi.org/10.1080/07908310008666606

Shaaban, K. (2005). English language teaching in Lebanon: Challenges for the future. In G. Braine (Ed.), Teaching English to the world: History, curriculum and practice (pp. 103-113). Mahwah, NJ: Lawrence Erlbaum Associates Incorporated.

Shaaban, K., \& Ghaith, G. (1997). An integrated approach to foreign language learning in Lebanon. Language, Culture and Curriculum, 10, 200-207. http://dx.doi.org/10.1080/07908319709525252

Shaaban, K., \& Ghaith, G. (1999). Lebanon's language-in-education policies: From bilingualism to trilingualism. Language Problems and Language Planning, 23, 1-16. http://dx.doi.org/10.1075/lplp.23.1.01leb

Shaaban, K., \& Ghaith, G. M. (2005). The theoretical relevance and efficacy of using cooperative learning in the ESL/EFL classroom. TESL Reporter, 38, 14-28.

Slavin, R. (1990). Cooperative learning: Theory, research, and practice. Boston: Allyn \& Bacon.

TESOL (1997). ESL standards for pre-K-12 students. Alexandria, VA: Author.

Van Ek, J. A. (1991) The threshold level for modern language learning in schools. Malaysia: Longman.

Weir, C. (1993). Understanding and developing language tests. New York: Prentice Hall.

Yaghi, R. (2012). Lebanon: A personal journey from professional development to GIS implementation in an English language classroom. In A. J. Milson, A. Demirci, \& J. Kerski (Eds.), International perspectives on teaching and learning with GIS in secondary schools (pp. 151-156). New York: Springer. http://dx.doi.org/10.1007/978-94-007-2120-3_17

Zakharia Z. (2010). Language-in-education policies in contemporary Lebanon: Youth perspectives. In O. Abi-Mershed (Ed.), Trajectories of education in the Arab world: Legacies and challenges (pp. 156184). New York: Routledge. 